\title{
Um primeiro estudo histórico e conceitual do seminário "Epistemologia e representações sociais", conduzido por Serge Moscovici e Denise Jodelet em 1994
}

\author{
A first historical and conceptual study of the workshop "Epistemology and social \\ representations", held by Serge Moscovici and Denise Jodelet in 1994
}

Brigido Vizeu Camargo ${ }^{1}$

\begin{abstract}
RESUMO: Este artigo apresenta uma síntese sistemática de um documento áudio de valor histórico: o seminário "Epistemologie et représentations sociales" de Serge Moscovici e Denise Jodelet (1994 - Paris). Por meio de uma análise documental, seu foco foi descrever os principais pontos considerados por Serge Moscovici, nas seis das dez sessões que estiveram sob sua responsabilidade, no que concerne a este paradigma teórico para traçar uma epistemologia do mesmo. A análise partiu de uma perspectiva enunciativa (sequencial), localizando os conceitos de cada sequência e suas articulações. Para isto empregou-se o software Atlas Ti. Os principais resultados indicam principalmente três pontos centrais para responder às críticas ao paradigma das representações sociais. O primeiro ponto refere-se ao problema da racionalidade e irracionalidade do conhecimento social, indicando a centralidade das crenças sociais. O segundo foi o problema da discursividade e da linguagem, como limitadores do entendimento das interações sociais e da comunicação. O terceiro ponto foi a recusa de Moscovici em se submeter à ortodoxia teórica e suas implicações para a pesquisa, o que resultou na valorização de um ecletismo teórico e metodológico no paradigma das representações sociais.
\end{abstract}

Palavras-chave: representações sociais; epistemologia; conhecimento natural; comunicação; crenças.

\begin{abstract}
This paper presents a systematic synthesis of an audio document of historical interest: the workshop "Epistemologie et représentations sociales" held by Serge Moscovici and Denise Jodelet (1994 - Paris). Through a documental analysis, a description of the main points considered by Serge Moscovici in the sections under his responsability is offered. These points concern the social representations paradigm in order to trace an epistemology about it. The analysis adopts an enunciative (sequential) perspective, locating the concepts of each sequence and their articulations with the aid of the Atlas.ti software. The main results indicate three central points in answer to critics by discursive psychology to the social representations paradigm. The first refers to the problem of rationality vs. irrationality of social knowledge, enhancing the centrality of social beliefs. The second regards the limits of discourse and language for understanding social interactions and communication. The third was Moscovici's refusal to submit himself to theoretical orthodoxy and its implications for research, which led to a theoretical and methodological eclecticism within the social representations paradigm.
\end{abstract}

Keywords: social representations; epistemology; natural knowledge; communication; beliefs.

\section{Introdução}

No ano universitário de 1993/1994, no contexto do programa de doutorado em Psicologia Social da École des Hautes Études en Sciences Sociales (EHESS), Serge Moscovici e Denise Jodelet ofereceram um seminário aos doutorandos da época. Seu título em francês

\footnotetext{
${ }^{1}$ Doutor em Psicologia Social; Professor Titular do Departamento de Psicologia da Universidade Federal de Santa Catarina Santa Catarina, Brasil. E-mail: brigido.camargo@yahoo.com.br.
} 
era: "Epistemologie et représentations sociales"2 (EHESS, 1993, 1994a) e seu conteúdo era sobre as posições epistemológicas envolvidas nas críticas à teoria representações sociais (Moscovici, 1976/1961). Foi uma oportunidade ímpar oferecida a uma nova geração de pesquisadores que mais tarde auxiliaram Denise Jodelet na difusão da teoria das representações sociais na própria França, no Brasil, no México, dentre outros países. Este seminário teve como objetivo discutir os aspectos epistemológicos destas críticas no âmbito do estudo da "Teoria das Representações Sociais" (TRS), a partir da reflexão epistemológica deste paradigma de pesquisa.

Já que aqui se busca uma reflexão epistemológica dos estudos sobre o fenômeno das representações sociais, depara-se com uma questão de partida: a denominada "Teoria das Representações Sociais" é efetivamente uma teoria, uma noção ou um paradigma teórico? Esta questão é controversa, como já se mostrou em outra publicação (Camargo, 2007).

Uma teoria, num sentido "popperiano" (Popper, 1978) envolve ideias que explicam um conjunto de fatos, liga um conjunto de ideias necessariamente a um conjunto de fatos (empiria). Uma noção é uma ideia ou conceito, ela é empregada como uma entidade mais elementar, consiste numa representação abstrata de uma realidade. Já um paradigma, no sentido empregado por Kuhn (1998) e no âmbito da Filosofia da Ciência, é um conhecimento que origina o estudo de um campo na ciência, oferecendo métodos e valores que são concebidos como uma referência inicial de base para um conjunto de estudos e pesquisas.

O termo noção além de restrito esbarra na recusa de Moscovici em indicar uma definição única do fenômeno das representações sociais. O termo teoria foi criticado no âmbito da Psicologia Social pela amplitude dos conhecimentos em torno do fenômeno (Jahoda, 1988). E o termo paradigma pode aumentar o real alcance das proposições de Moscovici, pois comumente é empregado na Filosofia da Ciência indicando movimentos mais abrangentes tais como: paradigma positivista, paradigma construtivista, etc. Mas mesmo assim, opta-se aqui pelo emprego do termo paradigma pois o estudo das RS afetou toda uma ciência especifica: a Psicologia Social, tanto na redefinição do seu objeto, como no emprego simultâneo de múltiplos métodos; oferecendo ainda um posicionamento original para as pesquisas em diversas disciplinas do conhecimento social (Camargo, 2015).

O interesse dos pesquisadores pelo Paradigma das Representações Sociais (PRS) justifica a divulgação deste seminário, realizado em 1994, não só pelo seu conteúdo, mas também por ter sido o penúltimo seminário aberto de Serge Moscovici no quadro da formação doutoral em Psicologia Social na EHESS. Conforme consulta nos arquivos da EHESS, nos três anos universitários subsequentes (1994-1995, 1995-1996 e 1996-1997) ele ofereceu um seminário intitulado: "Les sociétés pensent-elles? Idéologies et représentations sociales"3 (EHESS, 1994b, 1995, 1996).

Dispondo de gravações em áudio de aproximadamente 15 horas, envolvendo 10 sessões deste seminário; primeiramente pretende-se descrever neste artigo o conteúdo de parte destas sessões. Posteriormente objetiva-se disponibilizar na integra, sob a forma de livro, esta importante atividade conceitual para a história do PRS.

\footnotetext{
2 Epistemologia e representações sociais (Tradução do autor).

${ }^{3}$ As sociedades são pensantes? Ideologias e representações sociais (Tradução do autor).
} 
Como indica o próprio título do seminário, na maior parte destas 15 horas Serge Moscovici, mas também Denise Jodelet; trataram do marco teórico no estudo do fenômeno das representações sociais. Dois colaboradores do desenvolvimento do PRS, Uwe Flick e Jorge Correia Jesuino, foram convidados na época para também contribuir com este seminário. O material traz estas reflexões epistemológicas sob forma oral e dirigidas a um público restrito, mas presente. O seminário foi composto de 10 sessões com duração média de 1 hora e 30 minutos. As sessões aqui em foco são a no 1 (03/03/1994), no 2 (11/03/1994), no 3 (18/03/1994), no 7 (29/04/1994), no 8 (06/05/1994) e no 10 (03/06/1994). Todas foram ministradas por Serge Moscovici. As sessões no 4 (25/03/1994) e no 5 (01/04/1994) foram ministradas por Denise Jodelet; e a sessão no 6 (08/04/1994) e no 9 (20/05/1994) foram ministradas respectivamente por Uwe Flick e Jorge Correia Jesuíno.

Mesmo na época deste seminário, início dos anos 90, bem como mais tarde, foram desenvolvidas excelentes meta-analises do paradigma das representações sociais, como a feita por De Rosa (1994) e a de Jodelet (2008). E este artigo não tem objetivo de refazer o que já foi tão bem realizado. No entanto, uma análise deste seminário pode contribuir com a compreensão da "teoria" em si, já que, como observou Jodelet (1989), seu próprio autor sempre foi refratário a empregá-la com uma definição única e terminal do fenômeno que ela trata. Também pela especificidade desta situação, comunicação direta, de reflexões epistemológicas; este seminário apresenta um interesse próprio, voltado para os percursos da exposição e das argumentações, trazendo um gosto especial pelo conhecimento do PRS. Destaca-se aqui a novidade deste empreendimento, mas também sua continuidade, pelo fato de examinar um paradigma no seu processo de construção. Além disto, o interesse deste seminário envolve o momento histórico da Psicologia Social Europeia, característico do início dos anos 90; onde o PRS, dominante, sofria inúmeras críticas por parte de uma Psicologia Social Discursiva (Potter \& Litton, 1985; Ibáñez, 1992).

O objetivo geral deste artigo é oferecer uma síntese sistemática de parte deste documento oral, focalizando o desenvolvimento conceitual em torno do fenômeno das representações sociais e seus aspectos epistemológicos. Por meio de uma primeira aproximação, de natureza descritiva, buscaremos indicar provisoriamente quais pontos Serge Moscovici considerou para responder as críticas à nomeada "teoria das representações sociais", e quais críticas ele privilegiou nesta tarefa.

\section{Método}

Empregou-se uma análise documental do material em áudio. O seminário foi analisado de forma sequencial e temático-categorial, conforme indicações de Bardin (1991). Esta análise teve como apoio o software Atlas/ti, que originalmente foi influenciado pela grounded theory (análise que começa pelos dados), mas que pode ser empregado em diferentes estratégias de pesquisa. O Atlas/ti é um processador de textos, áudios, vídeos e fotos; possibilitando o trabalho com bases de dados relacionais, hipertextos (Muhr, 1991). Assim, ele facilita a interpretação envolvendo material oral, escrito ou visual.

O procedimento envolveu cinco etapas: 1) múltiplas audições do material, 2) localização e marcação dos tópicos gerais em sequências que compõem cada sessão, 3) localização e vinculação dos conceitos aos tópicos sequenciais, 4) descrição dos conceitos em tópicos e 5) análise conceitual a respeito paradigma das representações sociais. 


\section{Resultados}

Como já colocado, as sessões ministradas por Serge Moscovici foram seis: 1, 2, 3, 7, 8, 10. Na etapa 2 foram localizadas 12 sequências na primeira sessão.

Segundo a figura 1, as 4 primeiras sequências $(1.1,1.2,1.3$ e 1.4) trataram da crítica de perspectivas pós-modernas, segundo as quais o conceito de representação é idealista e a TRS foi influenciada pelo positivismo. A partir da sequência 5 (1.5) Moscovici se ocupou da origem da noção de RS, o conceito de representação coletiva de Durkheim e seu pensamento sociológico. Nesta sessão apareceu um primeiro aspecto central das RS, a questão das crenças e suas funções.

A sessão 1 se caracteriza pela presença da filosofia cartesiana e sua crítica, e pelo pensamento de Durkheim, que segundo Moscovici, foi pioneiro do movimento anticartesiano, na medida em que não separava a realidade da representação. À expressão "escândalo do pensamento social" Moscovici atribuiu ao fato do conhecimento cotidiano, considerado como irracional, ter importância capital na vida de uma sociedade onde impera a ciência e a técnica.

Ouvimos dizer com frequência que uma boa ciência deve começar oferecendo conceitos claros e bem definidos. Na verdade, nenhuma ciência, até mesmo a mais exata, procede desta maneira. Ela começa por ajuntar, ordenar e distinguir os fenômenos que surpreendem a todos, seja porque eles perturbam, seja porque são exóticos ou, finalmente, porque eles escandalizam. No entanto, há poucas coisas tão escandalosas para os homens que vivem em uma cultura que reivindica, como a nossa, a ciência e a razão, do que o espetáculo das crenças, das superstições ou dos preconceitos partilhados por milhões de homens. (Moscovici, 2013, p. 65). ${ }^{4}$

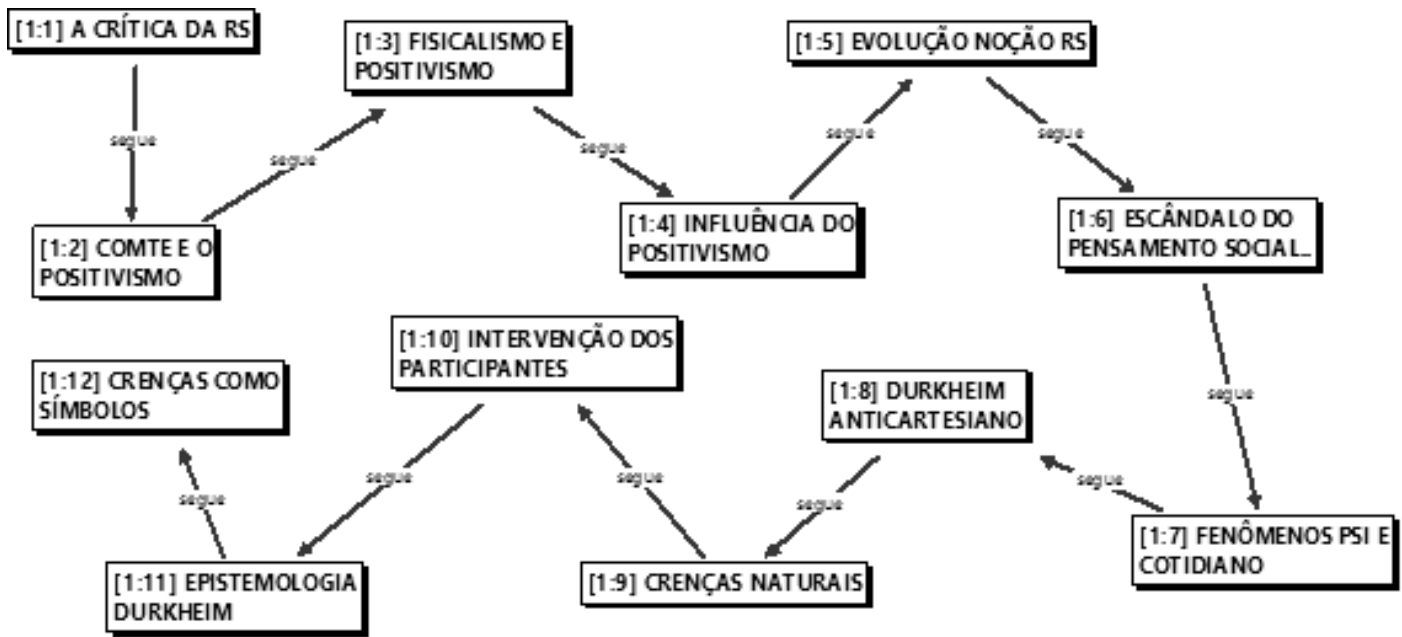

Figura 1 - Sequência de tópicos gerais da sessão 1

\footnotetext{
4 "Nous entendons souvent dire qu'une bonne science doit commencer par poser des concepts clairs et nettement definis. En verité alcune science, même la plus exacte, ne procède de cette manière. Elle commence par rassembler, ordonner et distinguer des phénomènes qui étonnent tout le monde, soit parce qu'ils dérangent, soit parce qu'ils sont exotiques, soit enfin parce qu'ils font scandale. Or, il y a peu de choses aussi scandaleuses pour les hommes vivant dans une culture qui se reclame, comme la nôtre, de la science et de la raison, que le spetacle des croyances, des superstions ou des préjugés que partagent millions d'hommes" (Texto original).
} 
A etapa 3 do procedimento de análise (ver Figura 2) indicou que os conceitos vinculados aos tópicos sequenciais que se destacam nesta primeira sessão foram: sociedade, crenças, irracionalidade, saber, valor, realidade, pensamento social. A sequência 6 (1.6Escândalo do pensamento social) integra os principais conceitos desta primeira sessão.

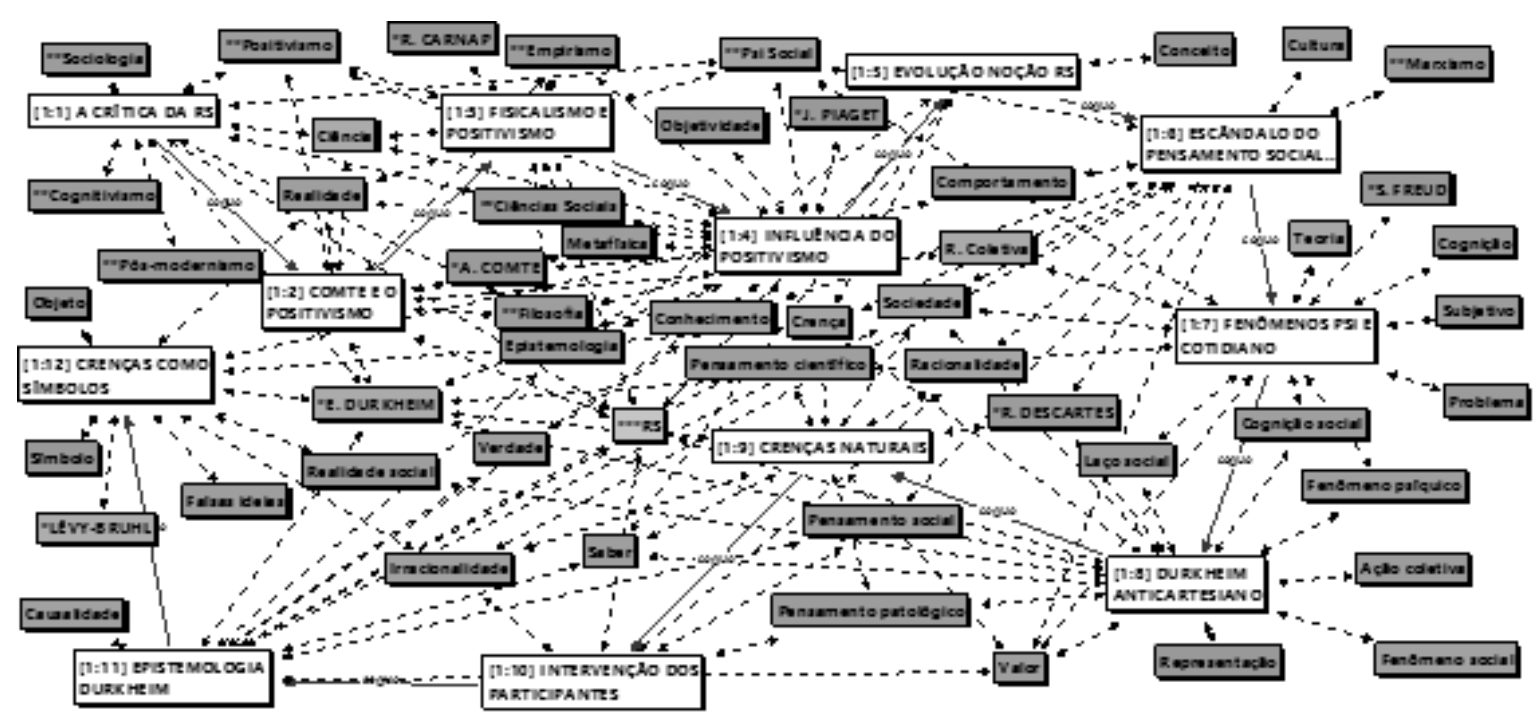

Figura 2 - Articulação dos tópicos sequenciais com os conceitos da sessão 1

Moscovici criticou expressões mais ortodoxas do behaviorismo e do marxismo pela forma como consideram o pensamento natural e cotidiano, ou seja: as crenças. Segundo ele, estes setores destas correntes do pensamento científico estabelecem uma hierarquização entre conhecimento e crença, onde a segunda noção é entendida como "conhecimento errado", expressão da irracionalidade, enquanto algo negativo. Para Moscovici, entender como as crenças estão tão presentes numa sociedade racional e científica, é uma indagação que o moveu a construção da "teoria das representações sociais".

A sessão 2 se caracterizou pela presença de 13 sequências. Conforme a figura 3, Moscovici continuou a desenvolver o conceito de representações coletivas de Durkheim, até a sequência 5 (2.5- Representações coletivas e sociologia). Mas ele observou que esta noção não era central na sociologia de Durkheim, e que esta foi outra razão que o chamou atenção para desenvolver uma teoria que contemplasse o pensamento coletivo cotidiano, enquanto uma parte do pensamento social.

Com a sequência 6 ele iniciou reflexões sobre a contribuição de Lévy-Bruhl para o entendimento das ideias primitivas, que mesmo atualmente nos chama atenção (Moscovici, 1994a). A continuidade desta sessão envolveu, sobretudo, os seguintes termos: ideias primitivas, crenças, racionalidade e pensamento coletivo. A partir desta sessão, por uma questão de espaço não apresentaremos sob a forma de gráfico a articulação dos tópicos sequenciais aos conceitos. 


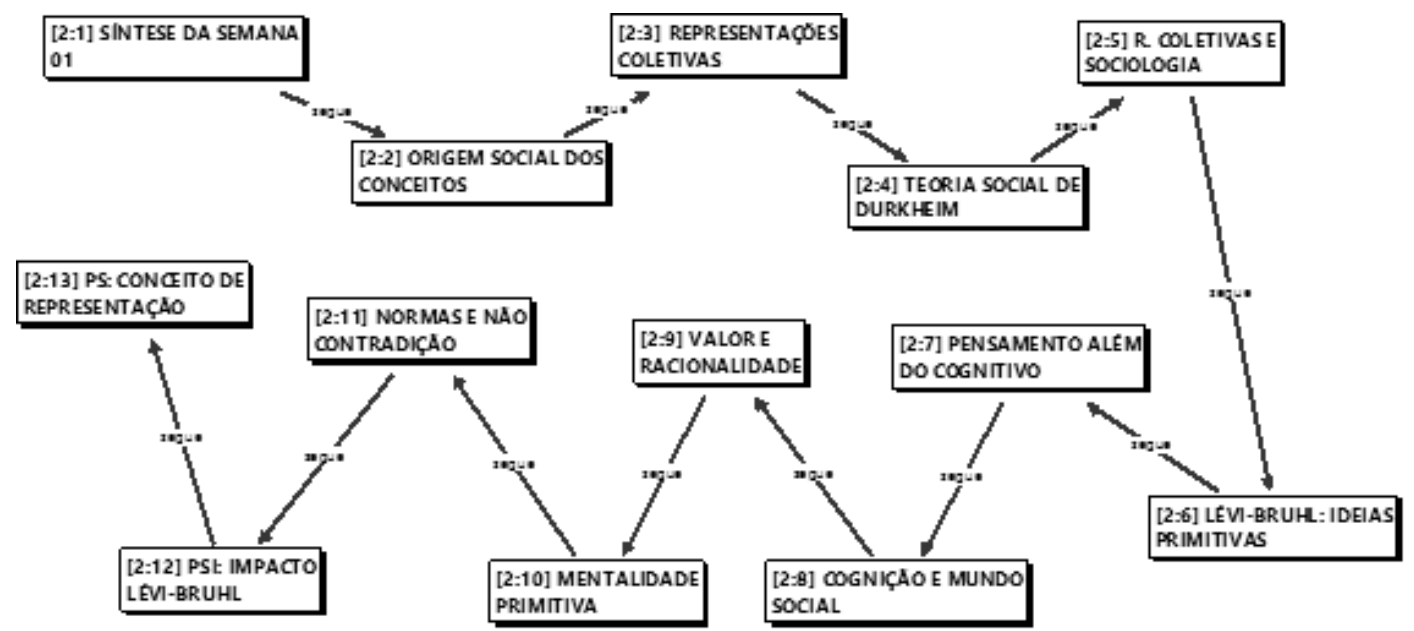

Figura 3 - Sequência de tópicos gerais da sessão 2

A sessão 3 compõe-se de 15 sequências. Conforme a figura 4, na primeira metade das sequências (até a sequência 6), a contribuição de Lévy-Bruhl foi considerada para a reflexão sobre o estatuto do conhecimento no pensamento científico e do pensamento coletivo em geral. $\mathrm{O}$ conceito de conhecimento e o de senso comum apareceram articulados com $\mathrm{o}$ pensamento científico e com o pensamento coletivo.

Nas sequências 7, 8 e 9; Moscovici criticou, mais uma vez, setores do marxismo e também as posições de natureza associacionista, como a psicologia cognitiva (Moscovici, 1993a), em função de suas posições quanto à hierarquização dos diversos tipos de conhecimento, e do problema relativo ao universalismo $\mathrm{x}$ particularismo.

Nas sequências 6 e 10 ele retomou a noção de representação social (apresentada na sessão 1 discorrendo sobre a importância do pensamento de Lévy-Bruhl para seu desenvolvimento e contrapondo-o ao marxismo, ao associacionismo e a psicologia cognitiva. A representação social foi apresentada como uma forma de conhecimento que envolve o pensamento coletivo e apresenta relações com o pensamento científico, mas voltado ao senso comum e a compreensão de atividades da vida cotidiana.

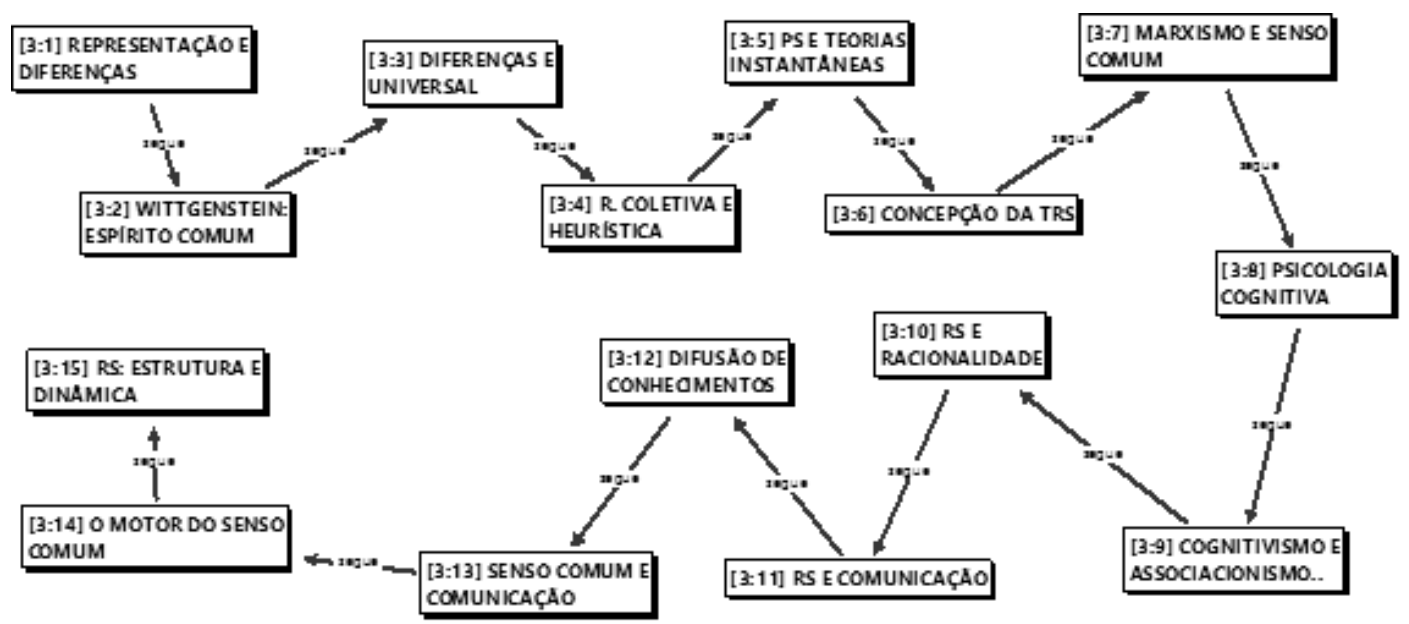

Figura 4 - Sequência de tópicos gerais da sessão 3

Como já mencionado anteriormente, entre a sessão 3 e a sessão 7 Denise Jodelet conduziu duas sessões (a 4 e a 5) e Uwe Flick apresentou sua contribuição (sessão 6). Nas 
três primeiras sessões, Moscovici tratou de aspectos filosóficos, tais como: o positivismo, o associacionismo, a racionalidade, o cotidiano, o senso comum, o princípio da não contradição, a ideia de universal, dentre outros. Mas, sobretudo, ele se ocupou de aspectos ligados às Ciências Sociais, tais como: crenças, representações coletivas, valor, instituições, conhecimento, comunicação, etc.

A sessão 4, conduzida por Denise Jodelet, focalizou críticas parciais à TRS, a saber: a consideração da noção ser vaga, ter um objetivo muito ambicioso, a crítica sobre a própria realidade do seu objeto (hipótese realista que sustenta a TRS) e a da vontade em continuar no campo tradicional da Psicologia Social (quadro neopositivista). E a sessão 5 deu atenção às críticas da Análise do Discurso concernentes a concepção de historicidade (particularismo) e a consideração de etnocentrismo na relação entre universo consensual e reificado; mas ainda as críticas do Construcionismo Social dirigidas, sobretudo, ao aspecto processual e histórico das representações sociais.

Na sessão 7, quando Moscovici retomou a condução do seminário, observou-se 16 sequências. Conforme a figura 5, Moscovici apresenta reflexões sobre a crítica da Análise do Discurso à noção de representações sociais. Os termos que se destacam nesta sessão são: discurso e conversação, de um lado; teoria e prática científica, de outro.

Aqui Moscovici nos ofereceu lições sobre a prática científica, como sua posição diante da rivalidade entre teorias e também o que ele chamou de ortodoxia metodológica. Da sequência 2 a 6 ele partindo da constatação de que o paradigma das representações sociais era dominante, caracterizou-o como voltado a realidade social que trata de um fenômeno complexo, exigindo uma abordagem multi-metodológica, qualitativa e quantitativa.

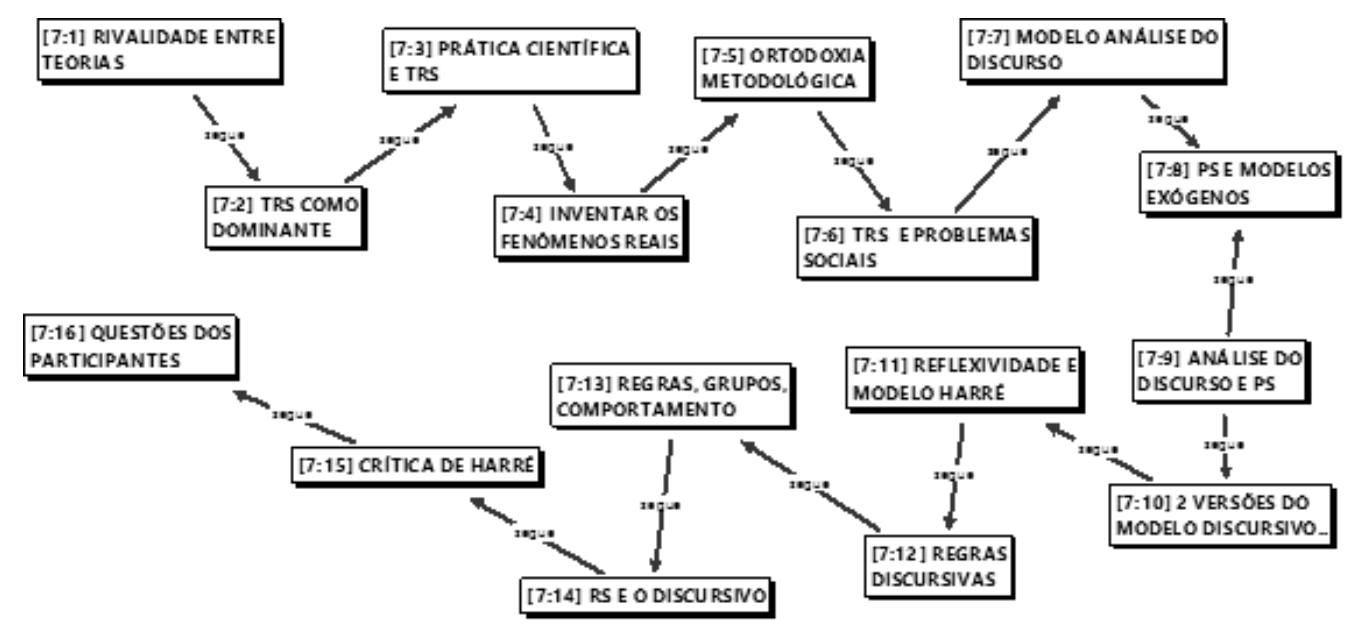

Figura 5 - Sequência de tópicos gerais da sessão 7

Ele criticou a interdição da Análise do Discurso aos métodos quantitativos. Nesta primeira parte da sessão 7 apareceu o que 20 anos mais tarde, em conversas pessoais, Moscovici chamou de "teóricortodoxia". Este neologismo pode ser especificado como a interdição, ou a própria auto interdição, da comunidade de pesquisadores em empregar mais de um desenvolvimento teórico para responder a um problema de pesquisa; o que gera proibições meta científicas, ou ideológicas, em nível metodológico, tais como: não usar determinados instrumentos de pesquisa como questionários padronizados, ou ainda não empregar análise quantitativa dos dados. 
A partir da sequência 7 ele centrou sua exposição na Análise do Discurso, considerando-a como uma área exógena à Psicologia Social. Ele destacou duas versões do modelo de Análise do Discurso: o de Greimas e de Harré. Focalizou o modelo discursivo de Harré e pontuou a crítica de Harré à noção de representações sociais. Nas sequências 12 e 13 ele diferenciou a forma como a Psicologia Social Discursiva tratava as regras, segundo ele separando o discursivo do social.

A sessão 8 apresenta 18 sequências. Conforme a figura 6 , nesta sessão todo o foco esteve no Modelo Discursivo, os termos chave são: discurso e linguagem. Moscovici apresentou uma leitura crítica da Análise do Discurso a partir de uma crítica mais geral ao pós-modernismo.

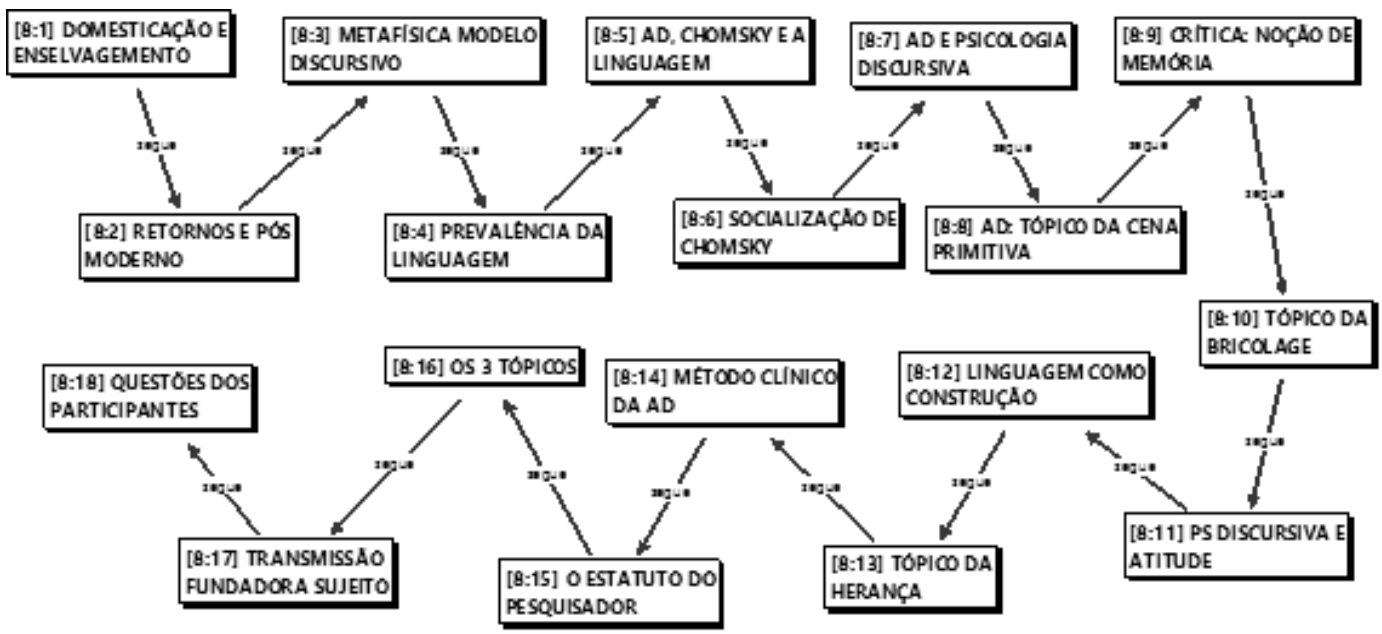

Figura 6 - Sequência de tópicos gerais da sessão

Ele considerou o pós-modernismo como uma série de retornos, sobretudo ao particular (sequências 1, 2 e 3). Na Análise do Discurso, segundo ele, a concepção de linguagem é, de certa maneira, restrita ao verbal. Nas sequências 8, 9, 10 e 11, Moscovici indicou problemas específicos à ideia de discurso na compreensão do fenômeno social. A concepção da linguagem como construção do sujeito (sequência 12), segundo ele, confere primazia ao subjetivo, característica do construtivismo (Gergen). Sua crítica nesta sessão foi mais contundente e se voltou a Potter e a Psicologia Discursiva. Ela trouxe implicações para a consideração da realidade social, como a de lhe atribuir uma natureza flutuante que não permite considerar a tradição.

Entre a sessão 8 e a sessão 10, Jorge Correa Jesuino apresentou sua contribuição ao tema (sessão 9). A sessão 10 compõe-se também de 18 sequências. Se na sessão anterior ele não associou diretamente sua leitura e crítica sobre a Análise do Discurso e o construtivismo ao paradigma das representações sociais, na sessão 10 ele o fez. Os termos que se destacam nesta sessão são: comunicação e linguagem, no lugar de discurso e linguagem (Moscovici, 1993b, 1994b).

Conforme a figura 7, Moscovici iniciou a sessão 10 (sequências 1 e 2) pontuando algumas críticas recebidas pela noção de representação social. Uma foi aquela a respeito do "círculo vicioso" entre grupo e representações, o primeiro depende da partilha de 
representações, e estas últimas tem origem nos grupos. Uma segunda foi sobre o possível papel do consensus como impedimento à criatividade e a mudança social.

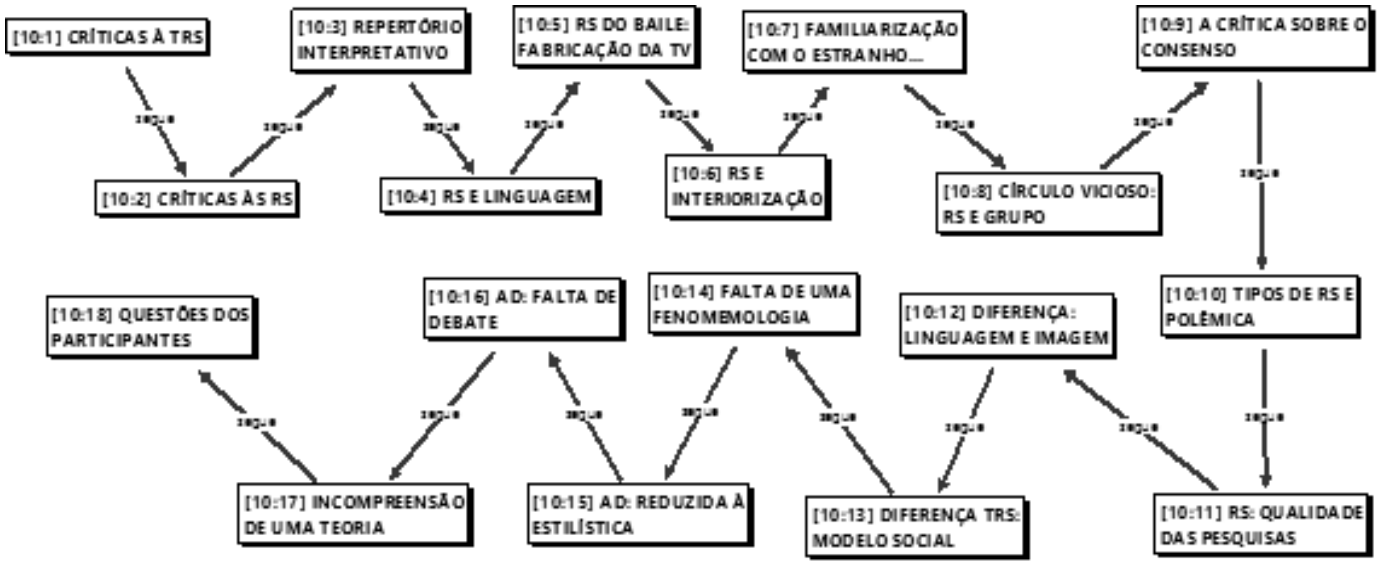

Figura 7 - Sequência de tópicos gerais da sessão 10

Outra ainda se referiu ao problema de familiarizar o estranho, como motor da criação de representações. Nas sequências seguintes ele respondeu a estas críticas (da sequência 5 a 10) enfatizando que as representações sociais são fenômenos de ordem social e não individual, neste sentido o laço social e os processos grupais se referem a uma realidade social que apresenta uma dimensão na intersecção entre o psíquico e o social.

Moscovici reconheceu que as críticas traziam pontos problemáticos deste paradigma, e que as pesquisas sobre representações sociais nem sempre tinham qualidade científica (sequência 11). No entanto para ele, o PRS refere-se a um fenômeno, possui uma fenomenologia, seu interesse reside nas relações sociais e não em indicadores sobretudo estilísticos de uma linguagem verbal que limita a comunicação humana (sequências 12 a 15). E concluiu no final desta última sessão (sequências 16 e 17) que não houve efetivamente um debate com os críticos da Análise do Discurso, pois não houve um lugar para este debate, na medida em que uma parte (a da $A D$ ) julgava que o discurso deste debate deveria seguir os preceitos do modelo que eles defendiam. Aqui apareceu uma contraposição implícita, mas muito importante, entre linguagem e comunicação.

\section{Discussão e conclusões}

Antes de apontar algumas questões sobre as seis sessões aqui consideradas, relembrase os pontos gerais destas sessões conduzidas por Serge Moscovici. Na primeira sessão ele iniciou sua exposição com críticas à noção de RS, explanou a noção de representações coletivas como ponto de partida para a elaboração deste paradigma. O conceito chave desta sessão é o de "crenças".

$\mathrm{Na}$ segunda sessão ele continuou a explanação e discussão da noção de representações coletivas, e passou a tratar do problema da racionalidade no conhecimento natural e no conhecimento científico. Aqui o conceito chave passou a ser o de "ideias primitivas". Na terceira sessão Moscovici continuou a tratar do problema da racionalidade e 
passou a trabalhar as ideias de conhecimento e senso comum. Aqui o ponto chave é "conhecimento".

Ele iniciou a sétima sessão com as críticas da $A D$, discorreu sobre o paradigma das RS e sua relação com os problemas sociais, expos uma leitura crítica sobre a AD. O ponto chave é a "conversação", que para Moscovici significava interação social em quadros reais de natureza grupal. Na oitava sessão ele continuou a expor sua crítica ao modelo discursivo e a Psicologia Social Discursiva. O ponto chave desta sessão é a "linguagem", ele criticou esta noção e também o subjetivismo do pós-modernismo neste domínio.

Na última sessão, a 10, Moscovici pontuou e respondeu as críticas da $A D$ ao paradigma das representações sociais. Reconheceu uma das várias críticas, aquela sobre o processo representacional e concluiu o seminário apontando a necessidade de se considerar mais este processo de formação das RS. O ponto chave desta sessão é o conceito de "comunicação", enquanto caracterizador da natureza social da abordagem do PRS.

Esta primeira aproximação das seis sessões analisadas pode indicar alguns aspectos que Serge Moscovici contemplou para responder as críticas ao paradigma das RS. No seu meticuloso trabalho em responder estas críticas trouxe o que considerava central para o paradigma teórico das representações sociais. As sessões, em vários momentos, traziam um relato de como ele fabricou este desenvolvimento teórico tão importante para a Psicologia Social. Observou-se ao longo deste seminário três aspectos bastante característicos do PRS. O primeiro diz respeito a fundação de um novo olhar sobre o problema da racionalidade e irracionalidade no âmbito do conhecimento natural. O segundo ponto é a perspectiva interacional na construção deste tipo de conhecimento, que coloca as concepções da Psicologia Social Discursiva, relativas a discursividade e a linguagem, como limitadoras do entendimento das interações sociais e da comunicação. E o terceiro foi a recusa de Moscovici em se submeter a ortodoxia teórica e suas implicações para a pesquisa, o que resultou na valorização de um ecletismo teórico e metodológico no paradigma das representações sociais.

O problema da racionalidade e irracionalidade do conhecimento social apareceu como central, ao longo de todo o seminário.

\begin{abstract}
Atualmente, dá-se destaque a uma teoria quando ela parece satisfazer muitas pessoas. Segundo esta teoria, os padrões de pensamento do homem da rua, o amador que somos, diferem daqueles do especialista; os primeiros cometem erros e empregam simplificações distorcem as deduções e os resultados. E essas distorções seriam atribuídas a fatores cognitivos. Ao contrário, a teoria das representações sociais assume que, por um lado, estes fatores têm uma origem social na divisão do trabalho entre leigos e especialistas e, por outro lado, devemos atribuir essas distorções às premissas pelas quais cada tira suas deduções. Mas essas premissas são compartilhadas e difundidas como representações sociais. Antecipamos a proposição de que essas representações levam a formas de pensar e diferentes tipos de dedução; da mesma forma que na ciência uma nova teoria leva a métodos e proposições que diferem dos da velha teoria. ${ }^{5}$ (Moscovici, 1992, p. 293)
\end{abstract}

\footnotetext{
5 “Actuellement, on accorde la prééminence à une théorie qui semble satisfaire beaucoup de gens. Selon cette théorie, les modes de pensée de l'homme de la rue, du novice que nous sommes, se distinguent de ceux de l'expert en ce que les premiers font des erreurs et emploient des raccourcis que déforment les dédutions et les résultats. Et ces déformations seraient à rapporter à des facteurs cognitifs. Par contre, la théorie des représentations sociales suppose que, d'une part, ces facteurs ont une origine sociale dans la division du travail entre novices et experts et que, d'autre part, il faut attribuer ces déformations aux premisses à partir desquelles chacun tire ses déductions. Mais ces premisses sont partagées et répandues comme les
} 
Isto confere ao conceito de crença um lugar central no paradigma das representações sociais. Segundo Moscovici, o interesse pelas representações sociais porta sobre algo "escandaloso" numa sociedade da informação, que pretendia substituir as crenças religiosas pelo conhecimento científico, que declarava guerra a irracionalidade das ideias e enaltecia a racionalidade que, no entanto, convive com o poder das crenças e superstições, religiosas ou não. O paradigma das representações sociais colocou uma alternativa bastante desenvolvida sob o ponto de vista metodológico para uma Psicologia Social mais societária, ao se interessar pela função destas crenças para a vida social dos crentes. Os leigos que compõem a sociedade deixaram de ser tomados por ignorantes e mal informados, para ser considerados como pessoas ativas, motivadas e interessadas, que constituem uma sociedade pensante.

O segundo aspecto, decorrente diretamente do contexto no início dos anos 90, foi o problema da discursividade e da linguagem como forma ideológica e de poder. A moda da Análise do Discurso, nas suas expressões mais radicais, tratou o paradigma das representações sociais como carente de uma abordagem processual e política. Moscovici, embora reconhecendo que as teorias competem, e que o próprio paradigma apresentava problemas quanto a compreensão do processo de elaboração e difusão das representações sociais, criticou esta Psicologia Social Discursiva contrapondo aos conceitos de "linguagem" e "subjetividade", os conceitos de "comunicação" e "relação social". O sujeito da linguagem nesta psicologia discursiva, para ele, era o indivíduo, enquanto para a dinâmica das representações sociais o sujeito é o grupo e as interações sociais neste quadro objetivo.

O terceiro aspecto, que atravessou várias sessões deste seminário, foi uma crítica à crítica da não observação da "teoriortodoxia" na produção do conhecimento sobre a realidade social. Moscovici não aceitou a interdição de leitura de certos autores e a proibição do uso de certos métodos e técnicas de pesquisa. Esta fluidez empregada no estudo do pensamento natural permitiu avanços teóricos e metodológicos para toda uma área do conhecimento: a Psicologia Social. Além destas contribuições decisivas para esta área, Serge Moscovici trouxe uma das principais respostas a sua crise de relevância: o olhar ternário para tratar seu objeto de estudo, o foco na interação que envolve um alter mediador entre um ego e o objeto; criticando os reducionismos psicológico e sociológico, existentes em setores mais ortodoxos do behaviorismo e do marxismo. 0 indivíduo foi entendido enquanto alguém que pensa, e não como mero respondente à um meio poderoso e condicionador, e nem mesmo como um simples resultado do assujeitamento às condições materiais de vida (Moscovici, 1976/1961, 1984). Estes seres pensantes foram entendidos como aqueles que acreditam, e a força destas crenças partilhadas nos grupos foram consideradas como um desafio ao ideário de uma "sociedade científica e técnica", um verdadeiro "escândalo social", como ele próprio denominou (Moscovici, 2013).

Recentemente, Jodelet remarcou que a amplitude das propostas de Moscovici tem permitido, a partir de uma abordagem teórica e metodológica, desenvolvimentos que indicam a fecundidade do paradigma das representações sociais. E observou que nas conclusões da obra fundadora deste paradigma ("A Psicanálise, sua imagem e seu público")

représentations sociales. On avance La proposition que ces représentations conduisent à des modes de pensée et à des genres de déduction différents, tout comme, dans la science, une nouvelle théorie conduit à des méthodes et à des propositions qui ce distinguent de celles de l'ancienne théorie" (Texto original). 
Moscovici reconheceu que a questão: "Como é que o homem constitui a sua realidade?", estava aberta (Jodelet, 2008, p. 427). E no final deste seminário também se deu algo similar: ele considerou que ainda faltava maior compreensão do processo de construção da realidade social do homem.

O presente trabalho é uma primeira aproximação em relação a um material complexo que porta sobre um tipo de reflexão bastante problemática, a saber: a epistemologia do paradigma das RS. O seu principal limite é a predominância do plano da descrição, mas também as dificuldades das interpretações. Isto se deve, entre outras, a duas razões: uma objetiva e outra subjetiva. A objetiva é a complexidade do material e do pensamento de Serge Moscovici, que embora prime a tradição cientifica, empregando também procedimentos contemplados pelo que se denomina positivismo e fisicalismo, foi um profundo critico desta perspectiva científica, especialmente na Psicologia Social. Este pensador apresenta um pensamento holístico e multidisciplinar, mas não "teóricortodoxo". A razão subjetiva refere-se a leitura feita neste presente artigo, que ainda é incipiente, preliminar, e de certa maneira linear, pois emprega o critério sequencial.

\section{Referências}

Bardin, L. (1991). L'analyse de contenu. Paris: P.U.F.

Camargo, B. V. (2007). O que o caminho interdisciplinar brasileiro da teoria das representações sociais não favorece? In A. S. P. Moreira \& B. V. Camargo (Orgs.). Contribuições para a teoria e o método de estudo das representações sociais (pp. 93-112). João Pessoa: Editora Universitária da UFPB.

Camargo, B. V. (2015). Serge Moscovici (14/06/1925 - 16/11/2014): um percussor inovador na Psicologia Social. Memorandum, 28, 240-245.

De Rosa, A. (1994). From theory to metatheory in social representation: The lines of argument of a theoreticalmethodological debate. Social Science Information, 33(2), 273-304.

EHESS (1993). Programme des enseignements et seminaires 1993-1994. Paris (p. 147).

EHESS (1994a). Annuaire- Comptes rendus des cours et conférences 1993-1994. Paris (pp. 537-538).

EHESS (1994b). Programme des enseignements et seminaires 1994-1995. Paris (p. 153).

EHESS (1995). Programme des enseignements et seminaires 1995-1996. Paris (p. 163).

EHESS (1996). Programme des enseignements et seminaires 1996-1997. Paris (p. 171).

Ibáñez, T. (1992). Some critical comments about the Theory of Social Representations. Ongoing Productions on Social Representations, 1(1), 21-26.

Jahoda, G. (1988) Critical notes and reflections on "Social Representation". European Jornal of Social Psychology, (18), 195-209.

Jodelet, D. (1989). Représentations sociales: Um domaine en expansion. In D. Jodelet (Org.). Les représentations sociales (pp.31-61). Paris: P.U.F.

Jodelet, D. (2008). Social representations: The beautiful invention. Journal for the Theory of Social Behaviour, 38(4), 411-430.

Kuhn, T. S. (1998). A estrutura das revoluções científicas. São Paulo: Perspectiva (Obra original publicada em 1962, 1970).

Moscovici, S. (1976). La psychanalyse, son image et son public. Paris: P.U.F. (Obra original publicada em 1961).

Moscovici, S. (1984). Psychologie sociale. Paris : Presses Universitaires de France. 
Moscovici, S. (1992). La mentalité prélogique des civilisés. In U. Flick (Org.). La percepcion quotidienne de la santé et de la maladie: Théories subjectives et représentations sociales (pp. 293-320). Paris: L'Harmattan.

Moscovici, S. (1993a). The return of the unconscious. Social Research, 60(1), 39-93.

Moscovici, S. (1993b). Toward a social psychology of science. Journal for Theory of Social Behavior, 23(4), 343374.

Moscovici, S. (1994a). La mentalité prélogique des primitifs et la mentalité prélogique des civilisés. In: S. Moscovici (Org.). Psychologie sociale des relations à l'autrui (pp. 208-231).

Moscovici, S. (1994b). Social representation and pragmatic communication. Social Science Information, 33(2), pp. 163- 177.

Moscovici, S. (2013). Le scandale de la pensée sociale. Paris: Éditions de l’EHESS.

Muhr, T. (1991). ATLAS/ti: A prototype for the support of text interpretation. Qualitative Sociology, 14(4), 34971.

Popper, K. (1978). Lógica das ciências sociais. Rio de Janeiro/Brasília: Tempo Brasileiro/Editora da UnB.

Potter, J., \& Litton. I. (1985). Some problems underlying the theory of social representations. British Journal of Social Psychology, 24, 81-90.

Apresentação: 08/12/2015

Aprovação: 15/02/2016 